Article

\title{
Developing a Preoperative Algorithm for the Diagnosis of Uterine Leiomyosarcoma
}

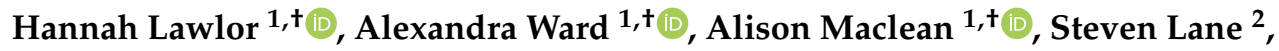 \\ Meera Adishesh ${ }^{1,3}$, Sian Taylor ${ }^{3}$, Shandya Bridget DeCruze ${ }^{3}$ and \\ Dharani Kosala Hapangama 1,3,* \\ 1 Department of Women's and Children's Health, Institute of Life Course and Medical Sciences, \\ University of Liverpool Member of Liverpool Health Partners, Liverpool L8 7SS, UK; \\ hl115@hotmail.co.uk (H.L.); Alexandra.ward294@gmail.com (A.W.); alison.maclean@liverpool.ac.uk (A.M.); \\ M.Adishesh@liverpool.ac.uk (M.A.) \\ 2 Department of Biostatistics, University of Liverpool Member of Liverpool Health Partners, \\ Liverpool L69 3BX, UK; slane@liverpool.ac.uk \\ 3 Liverpool Women's NHS Foundation Trust Member of Liverpool Health Partners, Liverpool L8 7SS, UK; \\ sian.taylor@lwh.nhs.uk (S.T.); shandyabdecruze@gmail.com (S.B.D.) \\ * Correspondence: dharani@liverpool.ac.uk; Tel.: +44-151-795-9553 \\ $\dagger$ These authors contributed equally to the work.
}

Received: 27 August 2020; Accepted: 19 September 2020; Published: 23 September 2020

check for updates

\begin{abstract}
Early diagnosis of the rare and life-threatening uterine leiomyosarcoma (LMS) is essential for prompt treatment, to improve survival. Preoperative distinction of LMS from benign leiomyoma remains a challenge, and thus LMS is often diagnosed post-operatively. This retrospective observational study evaluated the predictive diagnostic utility of 32 preoperative variables in 190 women who underwent a hysterectomy, with a postoperative diagnosis of leiomyoma $(n=159)$ or LMS $(n=31)$, at the Liverpool Women's National Health Service (NHS) Foundation Trust, between 2010 and 2019. A total of 7 preoperative variables were associated with increased odds of LMS, including postmenopausal status ( $p<0.001$, OR 3.08), symptoms of pressure $(p=0.002$, OR 2.7), postmenopausal bleeding ( $p=0.001$, OR 5.01), neutrophil count $\geq 7.5 \times 10^{9} / \mathrm{L}(p<0.001$, OR 5.72), haemoglobin level $<118 \mathrm{~g} / \mathrm{L}$ ( $p=0.037$, OR 2.22), endometrial biopsy results of cellular atypia or neoplasia ( $p=0.001$, OR 9.6), and a mass size of $\geq 10 \mathrm{~cm}$ on radiological imaging $(p<0.0001$, OR 8.52). This study has identified readily available and easily identifiable preoperative clinical variables that can be implemented into clinical practice to discern those with high risk of LMS, for further specialist investigations in women presenting with symptoms of leiomyoma.
\end{abstract}

Keywords: fibroid; leiomyoma; uterine leiomyosarcoma; uterine neoplasm; diagnosis

\section{Introduction}

Uterine leiomyomas, more commonly known as fibroids, are benign smooth muscle tumours of the uterus, which may cause pressure, heavy menstrual bleeding, pelvic pain, or be asymptomatic [1]. Usually identified in women of reproductive age, leiomyomas are common, with a reported prevalence ranging from 25 to $77 \%$ [2], and their incidence increases with advancing age [3]. A rare uterine malignancy, uterine leiomyosarcoma (LMS) shares many common features with benign uterine leiomyomas. LMS accounts for approximately $1-2 \%$ of uterine malignancies with a prevalence of 0.64 per 100,000 women [4]. However, the incidence of LMS in women undergoing a hysterectomy for suspected leiomyoma is much higher, at 1 per 1000 [5]. Although LMS occurs more frequently in postmenopausal women, in premenopausal women, key LMS-associated symptoms include vaginal 
bleeding, pelvic pain and pressure, thus clinical symptomatology is shared with leiomyomas $[1,3,4]$. Preoperative diagnosis of LMS is challenging, and currently there are no reliable diagnostic tools that are adequately sensitive enough to differentiate between LMS and benign uterine leiomyomas [6]. Most affected women are thus diagnosed postoperatively after histological examination of the uterus [7], which results in delayed and/or inappropriate treatment. Uterine leiomyomas are frequently managed conservatively, with a focus on symptom control, or with minimally invasive, limited surgical/nonsurgical procedures to preserve fertility, such as uterine artery embolization, magnetic resonance image (MRI)-guided transcutaneous focused ultrasound [8] and myomectomy. However, all of the above conservative treatments permit disease progression in a misdiagnosed LMS and can contribute to further reduction in cancer survival (12-25\% 5-year survival rate) $[5,9,10]$. Uterine leiomyoma is the indication in approximately $30-42 \%$ of all hysterectomies conducted for benign conditions [11], and laparoscopic route is preferred to decrease associated surgical morbidity and recovery time [12]. However, a laparoscopic approach may necessitate morcellation of the larger fibroid uteri [13]. If performed on an undiagnosed LMS, this poses the risk of dissemination, leading to iatrogenic upstaging of malignancy [14], and lower disease-free survival and poorer overall survival rate (10.8 months compared to 39.6 months) [15].

Accurate preoperative diagnosis of uterine LMS is needed to improve outcomes for women with LMS, and there is limited research in this area. Transvaginal ultrasound (TVUS) is frequently the first imaging modality employed to investigate uterine pathology; however, the sensitivity for detecting LMS is low, mostly due to similarities in sonographic appearance with leiomyomas [16,17]. Certain imaging features on computed tomography (CT) or magnetic resonance imaging (MRI) that are considered to be suggestive of malignancy have been investigated [18-20]; however, imaging characteristics that are highly predictive of LMS remain largely undefined. Elevated levels of tumour biomarkers cancer antigen 125 (CA-125) and lactate dehydrogenase (LDH) can be associated with malignancy, and they are often used in investigation of LMS despite poor sensitivity and specificity [21,22]. There are limited published data on the use of endometrial biopsy in diagnosis of LMS; however, some studies report diagnostic accuracy of up to $64 \%$ in LMS [23]. There is some evidence for the use of these multiple investigations in conjunction with each other to increase the predictive diagnostic value for LMS [24].

The main aim of this study was to evaluate the clinical predictive value of routinely and universally available preoperative variables to differentiate between malignant uterine LMS and benign leiomyomas in a cohort of women undergoing hysterectomy for symptomatic leiomyoma, and we subsequently identified 7 preoperative variables which can be used to stratify their risk of a diagnosis of malignant LMS, to consider further more advanced, specialist investigations such as MRI.

\section{Materials and Methods}

We conducted a retrospective observational study of two groups of women who had undergone a hysterectomy for symptomatic leiomyoma. Group 1 included all consecutive women who had been postoperatively diagnosed with LMS on histology, who underwent surgery between 2010 and $2019(n=31)$, and group 2 consisted of all consecutive women who underwent hysterectomy due to symptomatic leiomyoma, confirmed on histology, over a 12 month period from January to December in $2016(n=159)$. This was a single-site study, based at the Liverpool Women's NHS Foundation Trust (LWH), a tertiary gynaecological unit, where leiomyoma was documented as a primary indication for $43 \%$ of all hysterectomies carried out for benign gynecological causes during the study period (January-December 2016).

\subsection{Data Collection}

Collected patient data included the following: age, ethnicity, menopausal status, body mass index (BMI), parity, presenting symptoms, finding reported on preoperative imaging (ultra-sonographic scans (USS), CT, MRI), such as size of mass (if multiple masses present, the greatest diameter of largest mass was obtained), preoperative endometrial biopsy histology and preoperative blood results, including 
full blood count, LDH, and CA-125. Imaging and endometrial biopsies were obtained preoperatively, in the 3 months prior to hysterectomy. Blood tests were obtained $24 \mathrm{~h}$ prior to hysterectomy. Data were collected from electronic patient record databases and paper-based medical records and were anonymised prior to analysis. The LWH clinical team collected all the data included in this study, as part of service evaluation, assessing the standard of care at $\mathrm{LWH}$, and none of the patient identifiers were included. This study was approved by the gynaecological directorate audit committee at LWH (Service Evaluation Proposal submitted/approved by LWH Audit committee, approved on 14 September 2017) and did not require ethical approval from the adult research ethics committee.

\subsection{Statistical Analyses}

Data were analysed using SPSS 22.0 (IBM SPSS for Windows. Armonk, NY, USA). To investigate the relationship between the preoperative variables and the histological diagnosis of LMS, we performed a Chi-squared test or Fisher's Exact test and estimated the odds ratio (OR) and 95\% confidence interval (CI) on the statistically significant results. A $p$ value of $<0.05$ was considered to be statistically significant. Multivariate analysis was not carried out because of the small number of outcomes in the dataset $(n=31 \mathrm{LMS})$. Subgroup analysis based on menopausal status was not performed due to the small sample size.

\section{Results}

From a total of 32 preoperative variables (Supplementary Table S1), 7 were found to be significantly associated with increased odds of LMS (see Table 1). Patient demographics can be seen in Table 2.

Table 1. Comparison of preoperative parameters between leiomyoma and LMS groups.

\begin{tabular}{ccccc}
\hline Parameter & $\begin{array}{c}\text { No. LMA (\%) } \\
n=\mathbf{1 5 9}\end{array}$ & $\begin{array}{c}\text { No. LMS (\%) } \\
\boldsymbol{n}=\mathbf{3 1}\end{array}$ & $\boldsymbol{p}$-Value & OR (95\% CI) \\
\hline Postmenopausal & $39(24.7)$ & $30(56.7)$ & $<0.001$ & $3.08(1.61-5.91)$ \\
Pressure & $24(15.1)$ & $31(38.7)$ & 0.002 & $2.7(1.45-5.05)$ \\
PMB $^{*}$ & $13(33.3)$ & $17(82.4)$ & 0.001 & $5.01(1.62-15.54)$ \\
Atypia/neoplasia & $5(6.4)$ & $10(40)$ & 0.001 & $9.6(2.02-45.5)$ \\
$\mathrm{Hb}<118 \mathrm{~g} / \mathrm{L}$ & $28(25)$ & $30(56.7)$ & 0.037 & $2.22(1.04-4.74)$ \\
Neutrophil count $\geq 7.5 \times 10^{9} / \mathrm{L}$ & $9(8)$ & $30(33.3)$ & $<0.001$ & $5.72(2.06-15.87)$ \\
Mass $\geq 10 \mathrm{~cm}$ & $30(29.1)$ & $27(77.8)$ & $<0.001$ & $8.52(3.13-23.2)$ \\
\hline
\end{tabular}

LMA = Leiomyoma. $\quad$ LMS = Leiomyosarcoma. $\mathrm{OR}=$ Odds radio. $95 \% \mathrm{CI}=$ Confidence interval. $\mathrm{PMB}=$ Postmenopausal bleeding. $\mathrm{Hb}=$ Haemoglobin. ${ }^{*}=$ Sample size excluded premenopausal women.

Table 2. Patient demographic variables between leiomyoma and LMA groups.

\begin{tabular}{|c|c|c|c|c|}
\hline Demographic & Subcategory & No. LMA (\%) & No. LMS (\%) & $p$-Value \\
\hline \multirow{3}{*}{ Age } & $31-40$ years & $11(6.9)$ & $2(6.5)$ & \multirow{3}{*}{0.28} \\
\hline & $41-49$ years & $90(56.6)$ & $13(46.9)$ & \\
\hline & $>50$ years & $58(36.5)$ & $16(51.6)$ & \\
\hline \multirow{4}{*}{ Ethnicity } & White British & $141(88.7)$ & $26(96.3)$ & \multirow{4}{*}{0.53} \\
\hline & Asian British & $6(3.8)$ & $1(3.7)$ & \\
\hline & Black British & $2(1.3)$ & 0 & \\
\hline & Other & $10(6.3)$ & 0 & \\
\hline \multirow{4}{*}{$\begin{array}{l}\text { Body Mass Index } \\
\qquad\left(\mathrm{kg} / \mathrm{m}^{2}\right)\end{array}$} & $<20$ & $4(2.5)$ & 0 & \multirow{4}{*}{0.62} \\
\hline & $20-29$ & $84(52.8)$ & $17(56.7)$ & \\
\hline & $30-39$ & $62(40)$ & $10(33.3)$ & \\
\hline & $>40$ & $9(5.7)$ & $3(10)$ & \\
\hline \multirow{6}{*}{ Parity } & Nulliparous & $10(9.1)$ & $5(20)$ & \multirow{6}{*}{0.44} \\
\hline & 1 & $23(20.9)$ & $2(8)$ & \\
\hline & 2 & $49(44.6)$ & $13(52)$ & \\
\hline & 3 & $21(19.1)$ & $4(16)$ & \\
\hline & 4 & $5(4.6)$ & $1(4)$ & \\
\hline & $5+$ & $2(1.8)$ & 0 & \\
\hline \multirow{2}{*}{ Menopausal status } & Premenopausal & $119(75.3)$ & $13(34.3)$ & \multirow{2}{*}{$<0.001$} \\
\hline & Postmenopausal & $39(24.7)$ & $17(56.7)$ & \\
\hline
\end{tabular}

LMA = Leiomyoma. LMS = Leiomyosarcoma. 


\subsection{Menopausal Status and Symptomatalogy}

LMS group had a higher proportion of postmenopausal women $(p<0.001)$. Presenting symptoms such as pressure and postmenopausal bleeding (PMB) were more frequently associated with the LMS group ( $p=0.002$, OR 2.7, CI 1.61-5.05, and $p=0.001$, OR 5.01, CI 1.62-15.54, respectively, Table 1).

\subsection{Imaging}

Considering the size of the uterine mass on imaging, a diameter greater than $10 \mathrm{~cm}$ was significantly associated with LMS ( $p<0.0001$, OR 8.52, CI 3.13-23.2). Women with LMS were significantly more likely to have had a CT/MRI scan performed preoperatively than women with leiomyoma $(p<0.0001$, OR 9.89, CI 4.06-24.11), which emphasizes the importance of a clinician's suspicion in investigation of LMS. In cases of LMS with MRI $(n=9)$, the reports commonly included the following features: haemorrhage (33\%), necrosis (22\%), and heterogeneous enhancing signal (55\%). A standardized report proforma was not used. All MRI reports included the size and number of masses; however, only 5/9 included signal characteristics, 2/9 reported on necrosis or degeneration, and no reports commented on the perfusion pattern.

\subsection{Endometrial Biopsy Result}

A preoperative endometrial biopsy with a histological report of nuclear atypia or neoplasia was more likely in the LMS group ( $p=0.001$, OR 9.6, CI 2.02-45.4). In two of the cases with endometrial biopsy results suggestive of neoplasia, the reports stated "malignant neoplasm, widespread necrosis, sheets and islands of round and spindle cells," and "poorly differentiated malignant epithelioid tumour of unknown origin." In two other cases, LMS was diagnosed on preoperative endometrial biopsy; therefore, these were not included in the endometrial biopsy analysis.

\subsection{Blood Test Results}

Abnormalities in preoperative full blood count results were significantly associated with LMS, including a low haemoglobin $(\mathrm{Hb})$ level, defined as $\mathrm{Hb}<118 \mathrm{~g} / \mathrm{L}(p=0.037$, OR $2.22 \mathrm{CI} 1.04-4.74)$ and a neutrophilia, defined as neutrophils $>7.5 \times 10^{9} / \mathrm{L}(p<0.001$, OR 5.72, CI 2.06-15.87) (Figure 1). Normal reference ranges are detailed in Supplementary Table S2. CA-125 was performed in only 36\% of women $(n=68)$ and did not show a significant difference between groups. LDH levels were not recorded for any of the women included in this study.
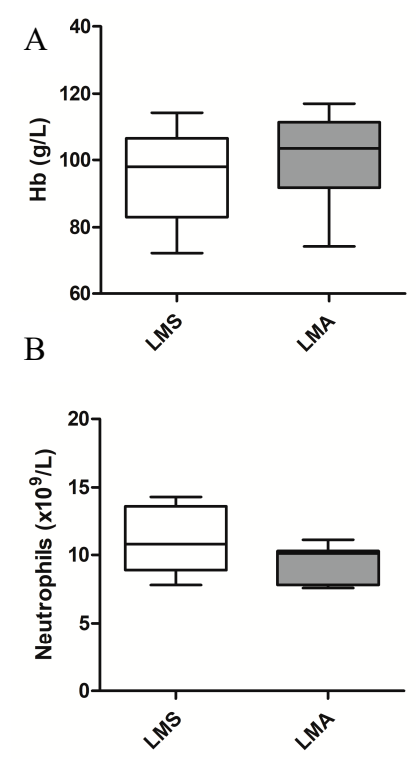

Figure 1. Box and whisker plots representing low haemoglobin $(\mathrm{Hb})$ and neutrophilia between leiomyoma (LMA) and leiomyosarcoma (LMS) groups. (A) Hb results for LMS and LMA groups. LMS: 
Median $=98,25 \%=83,75 \%=106.5, \operatorname{Min}=72, \operatorname{Max}=114,(n=17)$. LMA: Median $=103.5,25 \%=91.8,75 \%$ $=111.3$, Min = 74, Max = 117, $(n=28)$; (B) Neutrophil counts for LMS and LMA groups. LMS: Median $=10.8,25 \%=8.9,75 \%=13.6$, Min = 7.8, Max = 14.3, $(n=10)$. LMA: Median $=10.1,25 \%=7.8,75 \%=$ 10.3, Min = 7.6, Max = 11.1, $(n=9)$. Hb-haemoglobin, LMS-leiomyosarcoma, LMA-leiomyoma.

\section{Discussion}

This study demonstrates that when women present with common symptoms suggestive of either leiomyoma or LMS, those at a higher risk of LMS can be identified preoperatively, using demographic and clinical features and routine, noninvasive investigations. We propose that further investigation with MRI is warranted to exclude LMS when the 7 preoperative parameters we have identified are present in women with presumed symptomatic leiomyomas (Figure 2).

\section{Pre-operative variables that raise suspicion of LMS:}

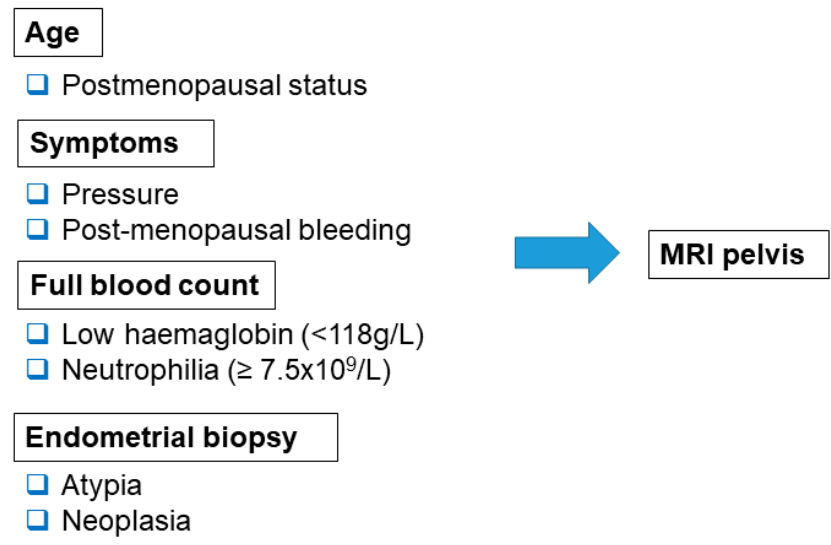

Figure 2. Pre-operative variables that should raise suspicion of LMS and prompt further imaging with MRI pelvis.

In keeping with current published literature, leiomyomas were more common in premenopausal women than in postmenopausal women in our study, while the opposite trend was observed in LMS [3,5]. Presenting symptoms such as PMB and pelvic pressure were significantly associated with LMS; hence, we propose that simultaneous presentation of PMB and pressure indicate the need for further investigation, with LMS as a differential diagnosis. Although we did not find age to be a significant differential feature for diagnosis of LMS in our study as others have [25], we did find that postmenopausal status was significantly associated with LMS. Increasing age may not have been of significance in this study as the population was relatively young. When older women, particularly those above 60 years of age, who present a decade or more after menopause, with an enlarged uterus, malignancy is routinely considered, as symptomatic leiomyomas are not frequently seen in this age group. However, an enlarged uterus with suspected leiomyoma is a regular feature in perimenopausal women, and thus often considered to be an incidental finding. The women included in our study were relatively young and at the end of their reproductive life, which we believe to be the clinically most useful time to discern benign leiomyomas from LMS. Therefore, our data identify determining variables in this particular age group, which is clinically relevant.

Blood tests are often performed preoperatively in suspected leiomyoma/LMS [26], but their value in differentiating between the two diagnoses has not yet been fully elucidated. Our data demonstrated that low $\mathrm{Hb}$ and neutrophilia are significantly associated with LMS. Our finding of an increased neutrophil count being associated with LMS is in keeping with published studies, which report a raised neutrophil-to-lymphocyte ratio and neutrophilia in preoperative diagnosis of LMS [27,28]. Further, preoperative findings of an elevated neutrophil-to-lymphocyte ratio has been associated with poor prognosis in other soft tissue sarcomas, and significantly associated with tumour size 
$\geq 5 \mathrm{~cm}$ [29]. A clear explanation of the role of neutrophilia in soft tissue sarcomas such as LMS has not yet been elucidated; however, some have proposed theories including the ability of neutrophils to produce proangiogenic factors [30,31], allowing tumour growth and angiogenesis. Further work is needed to clarify the relationship between neutrophilia and LMS. There are limited published data on the predictive role of CA-125 in LMS. Some studies report a potential role in differential diagnosis between early-stage and advanced-stage LMS and survival [32,33] and other larger studies reporting no predictive value for CA-125 in LMS and no association between stages [21]. We found no significant association between CA-125 and preoperative diagnosis of LMS in this study. As a CA-125 was only performed in a small number of our study population, we cannot reliably comment on the use of this as a preoperative tool for LMS. Although previous researchers have proposed LDH levels to be a beneficial biomarker with a readily accessible and low-cost test [34,35], no women in our cohort had an LDH recorded preoperatively, and therefore we were unable to assess its diagnostic validity for LMS.

Given that uterine LMS arises from the deep muscular myometrial layer of the uterus rather than the superficial, easily accessible endometrium, an endometrial biopsy is thought to be of limited clinical value. Although there are studies reporting low sensitivity in detecting LMS in endometrial biopsy $[1,35,36]$, our data suggest that our finding of atypical cells or neoplasia (without a known origin) on endometrial biopsy is significantly associated with LMS and likely to have some clinical value in preoperative diagnosis. Our findings are consistent with a large retrospective study reported preoperative endometrial sampling that suggested an invasive tumour in $86 \%$, and correctly predicted the histological diagnosis in $64 \%$ [23].

There are no currently validated radiographic criteria to differentiate between a leiomyoma and LMS [24,37]. MRI is considered to have moderate diagnostic accuracy in LMS [8,38] and can identify discriminating features of LMS such as degeneration or haemorrhage within the uterine mass [39]. Although some studies report that diffusion-weighted MRI can differentiate between the two diseases with high sensitivity [40], it is not universally available, and furthermore, more recent robust studies have identified that contrast-enhanced MRI has a higher diagnostic accuracy in reference to leiomyomas and LMS [41]. Agreeing with multiple other studies, our data illustrated that a greatest diameter of the largest uterine mass of $>10 \mathrm{~cm}$ was associated with LMS [10,24,42]. A mass of $<10 \mathrm{~cm}$ was more likely to be a leiomyoma. There is conflicting evidence on the efficacy of rate of tumour growth in differentiating between leiomyoma and LMS [24,34], and this was not analysed in our study; therefore, we cannot comment on its value in preoperative diagnosis of LMS. In this study, only 9 women with LMS had a preoperative MRI performed. Analysis of specialist radiological features of LMS on MRI imaging has been studied previously [43], and of the MRI reports available for patients included in our study, features such as necrosis, haemorrhage and heterogeneous signal intensity were often present. However, not all of the features associated with LMS were commented upon, and a standardized reporting proforma was not used.

LMS is a rare disease, and published studies thus tend to contain a small number of cases usually without a suitable control group. We present consecutive, contemporaneous data from a single, large specialist gynecological unit and included a relatively large cohort of women with LMS, as well as a comparator group of women with symptomatic benign leiomyomas, with a comprehensive amount of associated preoperative clinical variables. However, some of our confidence intervals are wide due to small numbers; therefore, some results may lack precision. It should be noted that the control group was comprised of all women with symptomatic leiomyoma undergoing hysterectomy; therefore, there is a need for future studies to prospectively evaluate these findings in women with suspected leiomyomas undergoing other treatment options. The clinical relevance of our findings should be validated in a prospective larger study of women with suspected leiomyoma, in a combined risk stratification model, where multivariate analysis can be utilised to create a clinical checklist that could stratify women for their risk of having LMS. 


\section{Conclusions}

Our study has identified a comprehensive panel of preoperative clinical features, biomarkers, diagnostic tools that differentiate between benign leiomyoma and LMS, which could easily be incorporated into clinical practice for risk stratification of women with occult LMS.

Supplementary Materials: Supplementary materials can be found at http://www.mdpi.com/2075-4418/10/10/ 735/s1. Supplementary Table S1: Summary of all pre-operative variables in leiomyoma and LMS groups. Supplementary Table S2: Normal reference ranges for blood results.

Author Contributions: D.K.H. conceived the manuscript. H.L., A.W., A.M., M.A., S.B.D. and D.K.H. collected the data. H.L., A.W., A.M., S.L., S.B.D., S.T. and D.K.H. analysed/interpreted the data, and H.L., A.W., A.M. and D.K.H. produced the first draft. All authors have read and agreed to the published version of the manuscript.

Funding: This research was funded by the University of Liverpool (H.L., A.W.), the Liverpool Women's Hospital Cancer Charity (M.A.), the Liverpool Women's Hospital NHS trust (M.A., S.T., S.B.D. and D.K.H.), Wellbeing of Women project grant numbers RG1487 and RG2137 (D.K.H.) and NIHR ACF (A.M.).

Acknowledgments: The authors are grateful to the women, clinical team members, audit and IT department at LWH for their invaluable contributions to this project.

Conflicts of Interest: The authors declare no conflict of interest.

\section{References}

1. Skorstad, M.; Kent, A.; Lieng, M. Uterine leiomyosarcoma-Incidence, treatment, and the impact of morcellation. A nationwide cohort study. Acta Obstet. Gynecol. Scand. 2016, 95, 984-990. [CrossRef]

2. Cramer, S.F.; Patel, A. The frequency of uterine leiomyomas. Am. J. Clin. Pathol. 1990, 94, 435-438. [CrossRef]

3. Stewart, E.A. Uterine fibroids. Lancet 2001, 357, 293-298. [CrossRef]

4. D'Angelo, E.; Prat, J. Uterine sarcomas: A review. Gynecol. Oncol. 2010, 116, 131-139. [CrossRef]

5. Giuntoli, R.L., 2nd; Metzinger, D.S.; DiMarco, C.S.; Cha, S.S.; Sloan, J.A.; Keeney, G.L.; Gostout, B.S. Retrospective review of 208 patients with leiomyosarcoma of the uterus: Prognostic indicators, surgical management, and adjuvant therapy. Gynecol. Oncol. 2003, 89, 460-469. [CrossRef]

6. Cui, R.R.; Wright, J.D.; Hou, J.Y. Uterine leiomyosarcoma: A review of recent advances in molecular biology, clinical management and outcome. BJOG Int. J. Obstet. Gynaecol. 2017, 124, 1028-1037. [CrossRef]

7. Wen, K.C.; Horng, H.C.; Wang, P.H.; Chen, Y.J.; Yen, M.S.; Ng, H.T. Uterine sarcoma Part I-Uterine leiomyosarcoma: The Topic Advisory Group systematic review. Taiwan J. Obstet. Gynecol. 2016, 55, 463-471. [CrossRef] [PubMed]

8. Tempest, N.; Hapangama, D. Should we be putting our scalpels down? Is HIFU the answer to fertility-sparing fibroid treatment? BJOG Int. J. Obstet. Gynaecol. 2018, 125, 366. [CrossRef] [PubMed]

9. Exacoustos, C.; Romanini, M.E.; Amadio, A.; Amoroso, C.; Szabolcs, B.; Zupi, E.; Adruini, A. Can gray-scale and color Doppler sonography differentiate between uterine leiomyosarcoma and leiomyoma? J. Clin. Ultrasound. 2007, 35, 449-457. [CrossRef] [PubMed]

10. Cho, H.Y.; Kim, K.; Kim, Y.B.; No, J.H. Differential diagnosis between uterine sarcoma and leiomyoma using preoperative clinical characteristics. J. Obstet. Gynaecol. Res. 2016, 42, 313-318. [CrossRef] [PubMed]

11. Lundholm, C.; Forsgren, C.; Johansson, A.L.; Cnattingius, S.; Altman, D. Hysterectomy on benign indications in Sweden 1987-2003: A nationwide trend analysis. Acta Obstet. Gynecol. Scand. 2009, 88, 52-58. [CrossRef] [PubMed]

12. Odejinmi, F.; Agarwal, N.; Maclaran, K.; Oliver, R. Should we abandon all conservative treatments for uterine fibroids? The problem with leiomyosarcomas. Womens Health (Lond.) 2015, 11, 151-159. [CrossRef] [PubMed]

13. Malzoni, M.; Perniola, G.; Hannuna, K.; Iuele, T.; Fruscella, M.L.; Basili, R.; Ebano, V.; Marziani, R. A review of 445 cases of laparoscopic hysterectomy: Benefits and outcome. Clin. Ter. 2004, 155, 9-12.

14. Ebner, F.; Friedl, T.W.; Scholz, C.; Schochter, F.; Janni, W.; Vorwerk, E.; DeGregorio, N. Is open surgery the solution to avoid morcellation of uterine sarcomas? A systematic literature review on the effect of tumor morcellation and surgical techniques. Arch Gynecol. Obstet. 2015, 292, 499-506. [CrossRef] [PubMed]

15. Perri, T.; Korach, J.; Sadetzki, S.; Oberman, B.; Fridman, E.; Ben-Baruch, G. Uterine leiomyosarcoma: Does the primary surgical procedure matter? Int. J. Gynecol. Cancer. 2009, 19, 257-260. [CrossRef] [PubMed] 
16. Gaetke-Udager, K.; McLean, K.; Sciallis, A.P.; Alves, T.; Maturen, K.E.; Mervak, B.M.; Moore, A.G.; Wasnik, A.P.; Erba, J.; Davenport, M.S. Diagnostic Accuracy of Ultrasound, Contrast-enhanced CT, and Conventional MRI for Differentiating Leiomyoma From Leiomyosarcoma. Acad Radiol. 2016, 23, 1290-1297. [CrossRef] [PubMed]

17. Sun, S.; Bonaffini, P.; Nougaret, S.; Fournier, L.; Dohan, A.; Chong, J.; Smith, J.; Addley, H.; Reinhold, C. How to differentiate uterine leiomyosarcoma from leiomyoma with imaging. Diagn Interv. Imaging 2019, 100, 619-634. [CrossRef]

18. Tirumani, S.H.; Ojili, V.; Shanbhogue, A.K.; Fasih, N.; Ryan, J.G.; Reinhold, C. Current concepts in the imaging of uterine sarcoma. Abdom. Imaging 2013, 38, 397-411. [CrossRef]

19. Cornfeld, D.; Israel, G.; Martel, M.; Weinreb, J.; Schwartz, P.; McCarthy, S. MRI appearance of mesenchymal tumors of the uterus. Eur. J. Radiol. 2010, 74, 241-249. [CrossRef]

20. Santos, P.; Cunha, T.M. Uterine sarcomas: Clinical presentation and MRI features. Diagn. Interv. Radiol. 2015, 21, 4-9. [CrossRef]

21. Yilmaz, N.; Sahin, I.; Kilic, S.; Ozgu, E.; Gungor, T.; Bilge, U. Assessment of the predictivity of preoperative serum CA 125 in the differential diagnosis of uterine leiomyoma and uterine sarcoma in the Turkish female population. Eur. J. Gynaecol. Oncol. 2009, 30, 412-414. [PubMed]

22. Babacan, A.; Kizilaslan, C.; Gun, I.; Muhcu, M.; Mungen, E.; Atay, V. CA 125 and other tumor markers in uterine leiomyomas and their association with lesion characteristics. Int. J. Clin. Exp. Med. 2014, 7, 1078-1083. [PubMed]

23. Bansal, N.; Herzog, T.J.; Burke, W.; Cohen, C.J.; Wright, J.D. The utility of preoperative endometrial sampling for the detection of uterine sarcomas. Gynecol. Oncol. 2008, 110, 43-48. [CrossRef] [PubMed]

24. Nagai, T.; Takai, Y.; Akahori, T.; Ishida, H.; Hanaoka, T.; Uotani, T.; Sato, S.; Matsunaga, S. Babaa, K.; Seki, H. Highly improved accuracy of the revised PREoperative sarcoma score (rPRESS) in the decision of performing surgery for patients presenting with a uterine mass. Springerplus 2015, 4, 520. [CrossRef] [PubMed]

25. Van den Bosch, T.; Ameye, L.; Van Schoubroeck, D.; Bourne, T.; Timmerman, D. Intra-cavitary uterine pathology in women with abnormal uterine bleeding: A prospective study of 1220 women. Facts Views Vis. Obgyn. 2015, 7, 17-24.

26. Adishesh, M.; Hapangama, D.K. Enriching Personalized Endometrial Cancer Research with the Harmonization of Biobanking Standards. Cancers 2019, 11, 1734. [CrossRef]

27. Kim, H.; Han, K.; Chung, H.; Kim, J.-W.; Park, N.; Song, Y.; Kang, S. Neutrophil to lymphocyte ratio for preoperative diagnosis of uterine sarcomas: A case-matched comparison. Eur. J. Surg. Oncol. 2010, 36, 691-698. [CrossRef]

28. Cho, S.; Cho, H.; Nam, A.; Kim, H.Y.; Choi, Y.S.; Park, K.H.; Cho, D.J.; Lee, B.S. Neutrophil-to-lymphocyte ratio as an adjunct to CA-125 for the diagnosis of endometriosis. Fertil Steril. 2008, 90, 2073-2079. [CrossRef]

29. Szkandera, J.; Absenger, G.; Liegl-Atzwanger, B.; Pichler, M.; Stotz, M.; Samonigg, H.; Glehr, M.; Zacherl, M.; Stojakovic, T.; Gerger, A.; et al. Elevated preoperative neutrophil/lymphocyte ratio is associated with poor prognosis in soft-tissue sarcoma patients. Br. J. Cancer 2013, 108, 1677-1683. [CrossRef]

30. Shamamian, P.; Schwartz, J.D.; Pocock, B.J.; Monea, S.; Whiting, D.; Marcus, S.G.; Mignatti, P. Activation of progelatinase A (MMP-2) by neutrophil elastase, cathepsin $\mathrm{G}$, and proteinase-3: A role for inflammatory cells in tumor invasion and angiogenesis. J. Cell Physiol. 2001, 189, 197-206. [CrossRef]

31. Schaider, H.; Oka, M.; Bogenrieder, T.; Nesbit, M.; Satyamoorthy, K.; Berking, C.; Matsushima, K.; Herlyn, M. Differential response of primary and metastatic melanomas to neutrophils attracted by IL-8. Int. J. Cancer 2003, 103, 335-343. [CrossRef] [PubMed]

32. Juang, C.M.; Yen, M.S.; Horng, H.C.; Twu, N.F.; Yu, H.C.; Hsu, W.L. Potential role of preoperative serum CA125 for the differential diagnosis between uterine leiomyoma and uterine leiomyosarcoma. Eur. J. Gynaecol. Oncol. 2006, 27, 370-374. [PubMed]

33. Huang, G.S.; Chiu, L.G.; Gebb, J.S.; Gunter, M.J.; Sukumvanich, P.; Goldberg, G.L.; Einstein, M.H. Serum CA125 predicts extrauterine disease and survival in uterine carcinosarcoma. Gynecol. Oncol. 2007, 107, 513-517. [CrossRef]

34. Nagai, T.; Takai, Y.; Akahori, T.; Ishida, H.; Hanaoka, T.; Uotani, T.; Sato, S.; Matsunaga, S.; Baba, K.; Seki, H. Novel uterine sarcoma preoperative diagnosis score predicts the need for surgery in patients presenting with a uterine mass. Springerplus 2014, 3, 678. [CrossRef] [PubMed] 
35. Hinchcliff, E.; Esselen, K.M.; Watkins, J.C.; Oduyebo, T.; Rauh-Hain, J.A.; Del Carmen, M.G.; Quade, B.J.; Muto, M.G. The Role of Endometrial Biopsy in the Preoperative Detection of Uterine Leiomyosarcoma. J. Minim. Invasive Gynecol. 2016, 23, 567-572. [CrossRef] [PubMed]

36. Leibsohn, S.; d'Ablaing, G.; Mishell, D.R., Jr.; Schlaerth, J.B. Leiomyosarcoma in a series of hysterectomies performed for presumed uterine leiomyomas. Am. J. Obstet. Gynecol. 1990, 162, 968-974; Discussion 74-76. [CrossRef]

37. Rothmund, R.; Huebner, M.; Joachim, C.; Hartkopf, A.; Fehm, T.; Bamberg, M.; Wallwiener, M.; Brucker, S.; Taran, F.-A. Clinical Characteristics, Surgical Management and Adjuvant Therapy of Patients with Uterine Leiomyosarcoma: 27 Years of Experience. Geburtshilfe Frauenheilkd. 2011, 71, 1085-1089. [CrossRef]

38. Lakhman, Y.; Veeraraghavan, H.; Chaim, J.; Feier, D.; Goldman, D.A.; Moskowitz, C.S.; Nougaret, S.; Sosa, R.E.; Vargas, H.A.; Soslow, R.A.; et al. Differentiation of Uterine Leiomyosarcoma from Atypical Leiomyoma: Diagnostic Accuracy of Qualitative MR Imaging Features and Feasibility of Texture Analysis. Eur. Radiol. 2017, 27, 2903-2915. [CrossRef]

39. Hricak, H. MRI of the female pelvis: A review. Am. J. Roentgenol. 1986, 146, 1115-1122. [CrossRef]

40. Tamai, K.; Koyama, T.; Saga, T.; Morisawa, N.; Fujimoto, K.; Mikami, Y.; Togashi, K. The utility of diffusion-weighted MR imaging for differentiating uterine sarcomas from benign leiomyomas. Eur. Radiol. 2008, 18, 723-730. [CrossRef]

41. Lin, G.; Yang, L.Y.; Huang, Y.T.; Ng, K.K.; Ng, S.H.; Ueng, S.H.; Lai, C.H. Comparison of the diagnostic accuracy of contrast-enhanced MRI and diffusion-weighted MRI in the differentiation between uterine leiomyosarcoma / smooth muscle tumor with uncertain malignant potential and benign leiomyoma. J. Magn. Reson. Imaging 2016, 43, 333-342. [CrossRef] [PubMed]

42. Oda, K.; Okada, S.; Nei, T.; Shirai, T.; Takahashi, M.; Sano, Y.; Shiromizu, K. Cytodiagnostic problems in uterine sarcoma. Analysis according to a novel classification of tumor growth types. Acta Cytol. 2004, 48, 181-186. [CrossRef] [PubMed]

43. Kubik-Huch, R.A.; Weston, M.; Nougaret, S.; Leonhardt, H.; Thomassin-Naggara, I.; Horta, M.; Cunha, T.M.; Maciel, C.; Rockall, A.; Forstner, R. European Society of Urogenital Radiology (ESUR) Guidelines: MR Imaging of Leiomyomas. Eur. Radiol. 2018, 28, 3125-3137. [CrossRef] [PubMed] 